\title{
Lateral Hypothalamus Contains Two Types of Palatability- Related Taste Responses with Distinct Dynamics
}

\author{
Jennifer X. Li, ${ }^{1,2 *}$ Takashi Yoshida, ${ }^{4,5 *}$ Kevin J. Monk, ${ }^{1,2}$ and Donald B. Katz ${ }^{1,2,3}$ \\ ${ }^{1}$ Volen National Center for Complex Systems, ${ }^{2}$ Department of Psychology, and ${ }^{3}$ Program in Neuroscience, Brandeis University, Waltham, Massachusetts \\ 02453, and ${ }^{4}$ Department of Molecular Physiology, ${ }^{5}$ Graduate School of Medical Sciences, Kyushu University, Fukuoka 812-8581, Japan
}

The taste of foods, in particular the palatability of these tastes, exerts a powerful influence on our feeding choices. Although the lateral hypothalamus (LH) has long been known to regulate feeding behavior, taste processing in LH remains relatively understudied. Here, we examined single-unit LH responses in rats subjected to a battery of taste stimuli that differed in both chemical composition and palatability. Like neurons in cortex and amygdala, LH neurons produced a brief epoch of nonspecific responses followed by a protracted period of taste-specific firing. Unlike in cortex, however, where palatability-related information only appears $500 \mathrm{~ms}$ after the onset of tastespecific firing, taste specificity in LH was dominated by palatability-related firing, consistent with LH's role as a feeding center. Upon closer inspection, taste-specific LH neurons fell reliably into one of two subtypes: the first type showed a reliable affinity for palatable tastes, low spontaneous firing rates, phasic responses, and relatively narrow tuning; the second type showed strongest modulation to aversive tastes, high spontaneous firing rates, protracted responses, and broader tuning. Although neurons producing both types of responses were found within the same regions of $\mathrm{LH}$, cross-correlation analyses suggest that they may participate in distinct functional networks. Our data shed light on the implementation of palatability processing both within LH and throughout the taste circuit, and may ultimately have implications for LH's role in the formation and maintenance of taste preferences and aversions.

\section{Introduction}

When we encounter a taste, we appreciate both its chemosensory properties and its palatability - the degree to which the taste is pleasurable or aversive. Recent work suggests that the processing of this complex taste experience may involve coordination between multiple brain areas (Grossman et al., 2008; Piette et al., 2012). Dissecting these interactions should reveal general principles underlying the organization and function of the taste system.

To deduce the nature of the relationships between areas, it is useful to compare the temporal properties of each area's responses. The taste system is highly conducive to such an approach, because different aspects of the taste experience-the simple presence of a taste on the tongue, its chemical identity, and its palatability - are reflected within distinct epochs of cortical and amygdalar responses (Katz et al., 2001; Sadacca et al., 2012). Behavioral manipulations targeting taste palatability selectively alter activity within the palatability-related response epoch (Fontanini and Katz, 2006; Grossman et al., 2008). Comparison of response dynamics across brain areas (Fontanini et al., 2009; Sadacca et al., 2012) has yielded predictive insight into cooperation

\footnotetext{
Received Aug. 17, 2012; revised April 23, 2013; accepted April 27, 2013.

Author contributions: T.Y. and D.B.K. designed research; J.X.L., T.Y., and K.J.M. performed research; J.X.L., K.J.M., and D.B.K. analyzed data; J.X.L. and D.B.K. wrote the paper.

This research was supported by the National Institutes of Health. We thank Emma Reid for technical assistance; and Brian Sadacca, Anan Moran, Madelyn Baez, and Vinod Rao for helpful comments and discussions.

*J.X.L and T.Y. contributed equally to this work.

Correspondence should be addressed to Jennifer X. Li, Brandeis University, Department of Psychology, Box 0624, 415 South Street, Waltham, MA 02453. E-mail: jennli@brandeis.edu.

DOI:10.1523/JNEUROSCI.3935-12.2013

Copyright $\odot 2013$ the authors $\quad 0270-6474 / 13 / 339462-12 \$ 15.00 / 0$
}

between the areas involved in palatability processing (Piette et al., 2012).

The lateral hypothalamus (LH), which interacts directly with multiple cortical and subcortical gustatory regions (Berthoud and Münzberg, 2011), is an attractive site for the further investigation of taste-response dynamics. LH is a powerful driver of feeding behavior: inactivation of LH leads to hypophagia (Anand and Brobeck, 1951; Grossman et al., 1978); electrical stimulation of LH drives both voracious eating (Hoebel and Teitelbaum, 1962; Margules and Olds, 1962) and production of orofacial behaviors typically associated with aversive tastes (Berridge and $\mathrm{Va}$ lenstein, 1991). It is reasonable to suggest that LH may play a role in processing the hedonic quality of taste stimuli.

A number of studies (Burton et al., 1976; Fukuda et al., 1986; Ferssiwi et al., 1987; Berridge and Valenstein, 1991; Grabenhorst et al., 2010) have directly implicated LH in palatability processing, but few have directly measured taste responses in individual LH neurons. Of these, some evidence exists for the presence of taste-specific, palatability-related responses in LH (Norgren, 1970; Schwartzbaum, 1988; Yamamoto et al., 1989), but nothing is known about how information relating to various aspects of the taste experience evolves over time within LH responses.

Here, we recorded single-unit activity in LH of awake rats while exposing them to five standard taste solutions. Our data demonstrate that, after a brief nonspecific epoch that likely signals the detection of taste stimuli on the tongue, $\mathrm{LH}$ responses (unlike those in cortex) primarily reflect palatability, concordant with the hypothesis that $\mathrm{LH}$ is important for processing the emotional aspects of taste stimuli. Furthermore, LH contains two populations of neurons with distinct palatability-related re- 
sponse properties: one best modulated by palatable stimuli, the other by aversive stimuli. These two populations appear to comprise separate functional networks, suggesting a dissociation in how $\mathrm{LH}$ processes pleasant versus aversive taste stimuli.

\section{Materials and Methods}

General and surgical procedures. Six adult (250-300 g) female LongEvans rats (Charles River Laboratories) served as subjects in the present study. Rats were maintained on a $12 \mathrm{~h}$ light/dark schedule, and sessions took place around the same time within the light period. All surgical and experimental procedures used in this study are in accordance with $\mathrm{Na}$ tional Institutes of Health guidelines and were approved in advance by the Brandeis University Institutional Animal Care and Use Committee.

Before the start of each experiment, we surgically implanted multiwire electrode bundles ( $25 \mu \mathrm{m}$ Formvar-coated nichrome wires, 16 wires per bundle) into LH using techniques described previously (Katz et al., 2001; Fontanini and Katz, 2006). In three animals, electrodes were implanted in only one hemisphere of $\mathrm{LH}$, while the remaining animals received bilateral electrode implants. To sample multiple regions within LH, we kept the mediolateral positions of the bundles fixed at $1.8 \mathrm{~mm}$ lateral to the midline, but varied the anteroposterior position of the electrodes across implantations, from -2.0 to $-3.5 \mathrm{~mm}$ with respect to bregma. The electrode tips were lowered to a depth of $8.0-8.3 \mathrm{~mm}$ below the surface of the brain. After the electrode bundles had been implanted, during the same surgical session, we affixed an intraoral cannula (IOC) to either side of the rat's skull. Each IOC consists of a hollow polyethylene tube inserted beneath the temporalis muscle terminating immediately anterolateral to the first maxillary molar (Grill and Norgren, 1978; Travers and Norgren, 1986), which allows controlled amounts of select taste solutions to be infused directly onto the dorsal surface of the rat's tongue.

Anesthesia was maintained throughout surgery via intraperitoneal injections of a ketamine/xylazine mixture ( $1 \mathrm{ml}$ ketamine, $0.05 \mathrm{ml}$ xylazine/kg body weight). After surgery, rats were given postoperative analgesics (Rimadyl, $4.4 \mathrm{mg} / \mathrm{kg}$ ) and antibiotics (penicillin, Pro-Pen-G; $150,000 \mathrm{U} / \mathrm{kg}$ ) for at least $2 \mathrm{~d}$, and were allowed to recuperate for $7 \mathrm{~d}$ before the start of the experiment. During the recovery period, rats were provided with ad libitum access to chow and water. To monitor the health of the animals, we weighed the rats daily during the recovery period and the ensuing taste experiment. Rats did not fall below $85 \%$ of their presurgery weight throughout the entire experiment.

Experimental design. We began each experiment by habituating the rats for at least $2 \mathrm{~d}$ to the behavioral chamber, the recording apparatus, and the delivery of fluids through the IOC. After the animals had been habituated, we performed daily recording sessions for a minimum of $5 \mathrm{~d}$ and a maximum of $9 \mathrm{~d}$ (mean length of session: $7 \mathrm{~d}$ ). During each recording session, we administered a pseudo-randomized sequence of five taste stimuli consisting of reagent-grade chemicals dissolved in distilled water.

We chose standard taste solutions [sweet: $300 \mathrm{~mm}$ sucrose (S); salty: $150 \mathrm{~mm}$ sodium chloride $(\mathrm{N})$; distilled water $(\mathrm{W})$; sour: $10 \mathrm{~mm}$ citric acid (C); and bitter: $2 \mathrm{~mm}$ quinine hydrochloride $(\mathrm{Q})]$ that varied in both chemical composition (and therefore in sensory properties) and hedonic quality. All non-water taste stimuli were well above behavioral thresholds, and while they may have varied somewhat in intensity, our concentrations generally fell within the range of intensities used by other research groups (100-1000 mm sucrose, $100 \mathrm{~mm}$ sodium chloride, 1-10 mu quinine, and 10-30 mu acid; for review, see Yamamoto et al., 1985; Frank et al., 2003; Geran and Travers, 2009; Chen et al., 2011; Rosen and Di Lorenzo, 2012). We did not attempt to present "iso-intense" stimuli because there is no consensus in the literature as to which concentration of sucrose would be the same as a particular concentration of quinine (the variability of concentrations used across the studies listed stands testament to this fact) - that is, no single, definitive neural or behavioral scale against which different stimuli can be normalized. Even within the realm of behavioral measures, stimuli described as maximal in intensity vary between tasks (e.g., contrast Travers and Norgren, 1986, which shows gape responses asymptoting near $1 \mathrm{~mm}$ quinine, with Reilly and Pritchard, 1996 and Bueter et al., 2011, which show consumption asymptoting at $\sim 0.03 \mathrm{~mm}$ quinine).
Taste solutions were delivered onto the tongue via a bundle of five polyimide tubes inserted through the IOC, with a separate tube for each solution. For each taste delivery, a brief $20 \mu \mathrm{l}$ pulse of the corresponding solution was infused out of the polyimide tube. The interval between deliveries varied uniformly between 20 and $40 \mathrm{~s}$, which is sufficiently long for the taste system to reset (A. Fontanini and D. B. Katz, unpublished observations). Taste solutions were presented in pseudo-randomized blocks to ensure even sampling of the five tastes. To ensure consumption during the recording sessions, rats were put on mild water restriction $(\sim 18 \mathrm{~h}$ of access to water each day in the home cage) starting from $1 \mathrm{~d}$ before the first recording session and lasting throughout all recording days.

Recording sessions typically lasted less than an hour and consisted of 15-20 repeats of each of the five taste stimuli, for a total of 75-100 separate taste deliveries. We have previously shown that palatability and neural responses are stable across this length of session and volume of fluid consumption (Fontanini and Katz, 2006). Although the general stimulus delivery design remained the same from day to day, the electrodes were sometimes moved in $0.075 \mathrm{~mm}$ increments between recording days to sample more of the LH neuropil, and to obtain fresh units for each recording session. Across all recording days, the electrodes were moved up to a total of $0.4-0.6 \mathrm{~mm}$ in depth (mean depth: $0.5 \mathrm{~mm}$ ).

At the end of the experiment, rats were deeply anesthetized with an overdose of the ketamine/xylazine mixture used in surgeries, and electrolytic lesions (via $7 \mu \mathrm{A} \mathrm{DC}$ current for $7 \mathrm{~s}$ ) were made to mark the locations of select electrode tips. We then perfused the rats with $10 \%$ formalin, harvested the brains, sectioned the brains at a thickness of 50 $\mu \mathrm{m}$, and stained the slices with cresyl violet (Sigma-Aldrich). The sections containing the electrode tracks and lesions were compared with a rat brain atlas (Paxinos and Watson, 2007), and we extrapolated from our records of the electrode movements across recording days to identify the anatomical locations of the recordings.

Palatability/preference data. Palatability of the tastes in our battery were determined using a brief-access test (for details, see Sadacca et al., 2012) run on a separate group of rats $(N=7)$ that underwent the same water restriction protocol as the rats used in the recording experiment. Consumption data were collected across 2 testing days, and averaged for each animal. The palatability/preference ordering determined by the brief-access test- $\mathrm{S}>\mathrm{N}>\mathrm{W}>\mathrm{C}>\mathrm{Q}$ (Fig. $1 B$ ) -is identical to that observed across a broad range of physiological conditions, stimulus delivery methods, and assessment techniques (Grill and Norgren, 1978; Travers and Norgren, 1986; Breslin et al., 1992; Galaverna et al., 1993; Stewart et al., 1994; Clarke and Ossenkopp, 1998; Dess, 2000; Fontanini and Katz, 2006; Sadacca et al., 2012).

It is highly unlikely that palatability was confounded with intensity in our experiment, because the reliable palatability ordering within our stimulus set does not covary with any of the putative neural and behavioral measures of taste intensity, such as the extent to which each taste activates the chorda tympani, or the number of orofacial movements produced in response to each taste (Grill and Norgren, 1978; Travers and Norgren, 1986; Formaker and Frank, 1996). In addition, our data (Fig. $1 C-E$; see also Fig. $5 A$ ) demonstrate that even though distilled water is the least intense stimulus within our array, it often produced an intermediate response in LH neurons. If LH neurons were actually encoding intensity, we would expect distilled water to elicit either the weakest or the strongest response.

Neural data collection and processing. During each recording session, 16 channels (one electrode bundle) or 32 channels (two bundles) of voltage data were sampled at $40 \mathrm{kHz}$, amplified, filtered, and recorded using hardware from Plexon Inc. From the raw voltage signals, we retained all waveforms that crossed a certain amplitude threshold and sorted these waveforms into individual unit clusters using threedimensional cluster cutting techniques (Offline Sorter, Plexon Inc.). Sorted waveform records were digitized at $1 \mathrm{kHz}$.

We characterized taste responses separately for each neuron, focusing on the $2750 \mathrm{~ms}$ of spiking activity immediately following each taste delivery (by this time, swallowing behaviors that eliminate the taste from the tongue make interpretation of neural responses increasingly difficult; see Travers and Norgren, 1986). To obtain the evoked response for a 
single taste delivery, we subtracted each millisecond of the spike train following delivery by the mean value of the spike train from the baseline period, defined as the $1500 \mathrm{~ms}$ immediately preceding delivery. All analyses for each neuron were performed on the full set of evoked responses collated across all deliveries of all five tastes.

Analysis of neural response properties-from more general to more specific. We analyzed a set of response properties varying from general to very specific: we first tested whether the neuron in question had any response to taste delivery at all (i.e., whether it was "taste responsive"); next, we tested whether these responses differed in any possible way across tastes (i.e., whether the responses were "taste specific"); finally, we tested whether the pattern of responses evoked by the five stimuli specifically reflected the palatability ordering of the stimuli (i.e., whether the responses were "palatability related"). Below, we describe each analysis in turn.

"Taste responsiveness" reflects the degree to which a neuron's activity conveys information concerning the general presence of a taste on the tongue. Taste responsiveness simply implies that firing rates deviate from baseline following taste delivery, and is thus determined using a one-sample Student's $t$ test: if baselinesubtracted responses (collated across all deliveries of all five tastes) differ significantly from zero, the neuron is deemed "taste responsive." In total, 87 of 128 neurons exhibited responses that were significantly taste responsive. As is often the case in sensory physiology, many (54) of these neurons show no significant modulation that was specific for a subset of stimuli; there are many possible sources of such responses - taste-induced arousal (Hagan et al., 1999; Hassani et al., 2009), somatosensory activity (Katz et al., 2001), or even auditory response to solenoid opening (Norgren, 1970); regardless, nonspecific responses were outside the scope of this investigation, and such neurons were not studied further.

Taste-specific responses, by definition, allow discrimination of at least a subset of the five distinct taste stimuli-that is, the response to at least one taste differs significantly from the response to at least one other taste. To test for taste specificity, we used a one-way ANOVA in which the factor was the chemical identity of the taste solution: a significant effect indicates that the response to at least one taste is different from the response to at least one other taste. Note that this analysis is more exacting than that for taste responsiveness, as the former requires only that responses occur, and not that any be statistically distinct from another; thus, a neuron that is taste specific is likely also taste responsive, but the reverse is not necessarily true, and thus fewer neurons will be significantly taste specific than taste responsive in any dataset. However, also note that a broad variety of firing patterns $(\mathrm{N}>\mathrm{S}=\mathrm{Q}=\mathrm{C}=\mathrm{W} ; \mathrm{W}=\mathrm{C}=\mathrm{N}>$ $\mathrm{S}=\mathrm{Q} ; \mathrm{Q}>\mathrm{C}>\mathrm{W}>\mathrm{N}>\mathrm{S}$; to list a few) can confer taste specificity. In total, 35 of 128 neurons exhibited responses that were significantly taste specific.

Finally, palatability-related responses were those that not only differed depending on which taste was delivered, but did so in a very specific manner-increasing (or decreasing) with the palatability of the taste. To identify such responses, we computed the rank correlation $(r)$, across all taste deliveries, between the evoked response and the palatability of the associated taste ( $t$ tests were used to evaluate the significance of $r$ ). Note that this analysis is more exacting than that for taste specificity, as the former requires only that responses be different from one another, and not that they be ordered in any particular way; thus, any palatability- related response is likely also to be taste specific (although the difference between an ANOVA and Pearson correlation ensures that this will not always be the case). The reverse, meanwhile, is not necessarily true (given the huge number of response patterns that confer taste specificity, there is no particular reason to expect a taste-specific response to be palatability related a priori), and thus fewer neurons will be significantly palatability related than taste specific in any dataset. In total, 30 of 128 neurons exhibited responses that were significantly palatability related-a percentage that is higher than or comparable to the total percentage of taste-specific neurons reported in other taste areas, such as gustatory cortex (GC) and the amygdala (Nishijo et al., 1998; Katz et al., 2001; Fontanini et al., 2009).

Correlational analysis similar to that used here has been used elsewhere to study palatability in taste- and smell-induced electrophysiological and BOLD activity (Nishijo et al., 1998; Anderson et al., 2003; Small et al., 2003; Haddad et al., 2010), to categorize taste responses more generally (Frank, 2000; Spector and Travers, 2005), and to characterize other relationships between neural activity and perceptual properties (Blood et al., 1999; Roitman and Shadlen, 2002; for just a few of countless examples, see Ogawa et al., 2013). In our laboratory, this specific approach has been used to reliably and repeatedly identify responses that shift from being purely taste specific to being palatability related: the first $500 \mathrm{~ms}$ of taste-specific cortical responses are generally not palatability related, whereas later portions are strongly palatability related (Katz et al., 2001; Piette et al., 2012; Maier and Katz, 2013). In summary, if LH responses were not truly palatability related, only a chance few response patterns would correlate significantly with palatability, which is contrary to our observations. 
A
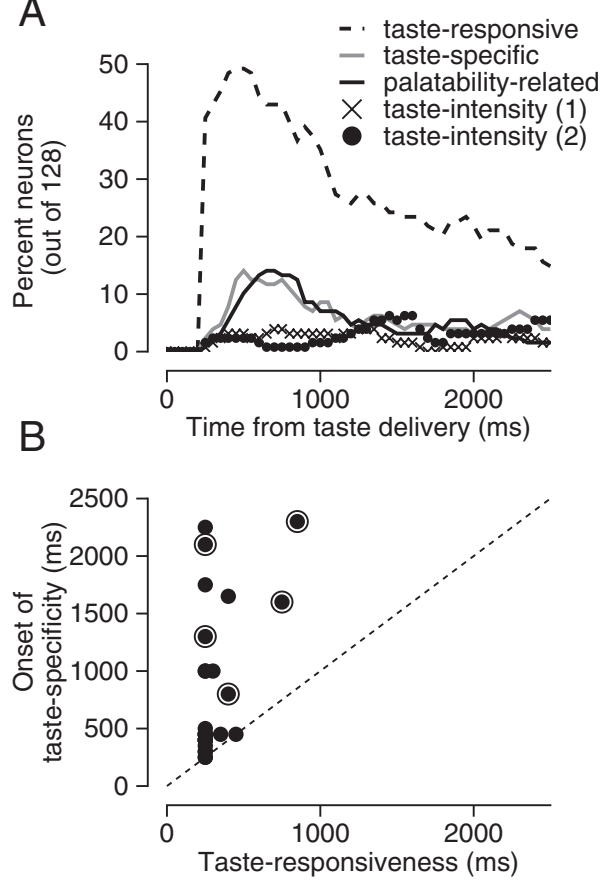

Figure 2. Time course of neural responses relating to different aspects of the taste experience. $\boldsymbol{A}$, Each line represents the percentage of LH neurons with responses that were significantly taste responsive (dashed line), taste specific (gray line), or palatability related (black line) as a function of time with respect to taste delivery. The lines with $X$ s and 0 s represent the percentage of neurons whose responses exhibit statistically significant rank correlations with two different taste intensity functions $(S=Q>$ $\mathrm{N}=\mathrm{C}>\mathrm{W}$ for the $\mathrm{Xs} ; \mathrm{Q}>\mathrm{S}>\mathrm{C}>\mathrm{N}>\mathrm{W}$ for the $0 \mathrm{~s}) . \boldsymbol{B}$, For the 27 neurons with both significant taste-responsive and taste-specific responses, the onset of taste specificity ( $y$-axis) is plotted against the onset of taste responsiveness ( $x$-axis). C, For the 23 neurons with both significant taste-specific and palatability-related responses, the onset of palatability relatedness ( $y$-axis) is plotted against the onset of taste specificity ( $x$-axis). In both $B$ and $C$, each symbol corresponds to the measurements from a single neuron, symbols with halos denote neurons with inhibitory responses, and the dashed diagonal line represents the unity line. All times are relative to taste delivery. $\boldsymbol{D}$, The distribution of best stimuli for all $42 \mathrm{LH}$ neurons with significant taste-specific responses, palatability-related responses, or both. The height of each bar indicates the number of neurons that responded most strongly to that particular taste.

Finally, we also examined the possibility that LH responses are correlated with a "motivation/intensity" function - that is, whether any neurons respond strongly to $300 \mathrm{~mm}$ sucrose and $2 \mathrm{~mm}$ quinine (both of which can be used to strongly motivate behavioral change), and less to stimuli that are less effective for driving behavior (Grill and Norgren, 1978; Travers and Norgren, 1986; Bueter et al., 2011). Specifically, we probed for response correlations with two intensity functions: $\mathrm{S}=\mathrm{Q}>$ $\mathrm{N}=\mathrm{C}>\mathrm{W}$, and $\mathrm{Q}>\mathrm{S}>\mathrm{C}>\mathrm{N}>\mathrm{W}$; vanishingly few $\mathrm{LH}$ response patterns were significantly correlated with either of these two functions (Fig. 2A).

Analyzing neural response dynamics. To probe the dynamics of tasteresponsive, taste-specific, and palatability-related firing for a given $\mathrm{LH}$ neuron, each of the above tests was applied to successive time windows of that neuron's evoked responses (window size, $500 \mathrm{~ms}$; step size, $50 \mathrm{~ms}$; span, $0-2750 \mathrm{~ms}$ relative to taste delivery). Statistical significance was evaluated at a $p$ value of 0.01 , but only when a stretch of at least three successive windows reached this threshold was that stretch deemed taste responsive, taste specific, and/or palatability related. Testing of baseline periods revealed that a threshold of three successive time points completely eliminated spurious significances (one or two successive time points produced, respectively, $10-12$ or $3-5$ neurons with spurious significances); however, our general conclusions are robust to the choice of threshold.

A number of analytical checks further increased our confidence in our conclusions. First, we confirmed that lowering the significance threshold for each window from $p<0.01$ to $p<0.001$ or decreasing the window size in the moving window analysis from 500 to $250 \mathrm{~ms}$ had no qualitative impact on any of our results. In addition, to determine whether serial correlations between deliveries could have affected our results, we computed the autocorrelation function of each neuron's responses across successive taste deliveries. Across all neurons, across all lags, the correlation almost never $(<1 \%)$ rose above 0.2 , or dipped below -0.2 . Finally, although recent work suggests that distilled water may be best thought of as a basic taste (Rosen et al., 2010), we confirmed that our main findings remained unchanged even after we had excluded neural responses to water from our analyses.

Handling inhibitory responses. Some LH neurons were inhibited by taste stimuli. Because (1) these neurons were in the minority, making up only $26 \%$ (9/35) of the neurons with tastespecific responses; (2) all of our analyses essentially dealt with the magnitude rather than the direction of evoked responses; and (3) our findings were similar across neurons with both excitatory responses and inhibitory responses, we combined the two groups in our final analyses (removing neurons with inhibitory responses did not alter our conclusions). We have, however, differentially labeled the two types of neurons in a subset of our figures (Figs. $2 B, C, 3 C, 4 A$ ).

Analysis of functional connectivity. To calculate the strength of the functional connectivity between simultaneously recorded pairs of neurons, we computed the millisecond-bymillisecond cross-correlogram between the two spike trains for each taste delivery, and averaged the result across all taste deliveries. We refer to the outcome of this procedure as the "raw cross-correlogram." To remove components in the raw cross-correlogram that are associated with the taste stimulus and the firing rates of the two neurons, we permuted the order of the taste deliveries for one of the neurons and recalculated the cross-correlograms from the shuffled data. We averaged the shuffled cross-correlograms across 1000 separate permutations and subtracted the shuffled average from the raw cross-correlogram, the result of which we call the "shuffle-corrected cross-correlogram." The strength of the functional connectivity was taken to be the peak height of the shufflecorrected cross-correlogram between -10 and $10 \mathrm{~ms}$. The same calculation was performed on the shuffled cross-correlograms, and the 99th percentile of the resulting distribution of peak heights served as the cutoff for statistical significance of the functional connectivity measured between a given pair of neurons. We computed the functional connectivity separately for the baseline period, which for this analysis spanned the last $2500 \mathrm{~ms}$ of the spike train preceding taste delivery, and for the evoked period, which spanned the first $2500 \mathrm{~ms}$ following taste delivery.

\section{Results}

\section{LH responses reflect first the presence, and then the palatability, of proffered tastes}

We measured taste responses from a total of $128 \mathrm{LH}$ neurons across six rats (mean \pm SEM: $2.3 \pm 0.24$ neurons/bundle/session). The responses (Fig. 1C-E, top panels, spike rasters, bottom panels, peristimulus time histograms) of three representative $\mathrm{LH}$ neurons to the five stimuli are shown in Figure $1 C-E$. For all three neurons, the initial portion of the response was highly similar across all tastes, and thus uninformative about either the chemical identity of the stimulus or its palatability. In other words, the earliest taste-induced activity was simply significant but nondis- 
tinctive taste responsiveness (Fig. $1 C-E$, bottom, light gray horizontal lines).

By approximately $250-500 \mathrm{~ms}$ after taste delivery, the responses in Figure 1, $C$ and $D$, had become taste specific (darker gray lines). Furthermore, both examples became palatability related at approximately the same time (darkest gray lines). Specifically, the neuron in Figure $1 C$ responded preferentially to the most palatable taste (sucrose, brown line), less to the second most palatable taste (sodium chloride, red line), and scarcely at all to the three least palatable tastes (water, citric acid, and quinine); each evoked response in Figure $1 C$ was short lived, returning to baseline within $1000 \mathrm{~ms}$ of taste delivery. In contrast, the neuron in Figure $1 D$ produced slowly building, long-lasting excitatory responses to all five tastes, but was most strongly activated by the least palatable taste (quinine), less by more palatable tastes, and least of all by the most palatable taste, sucrose; the response to quinine could be detected for $>2000 \mathrm{~ms}$ following stimulus delivery. Finally, the neuron shown in Figure $1 E$ also produced longlasting responses that were palatability related; these responses, like those in Figure $1 D$, were strongest to aversive tastes- but were in the inhibitory direction (note that a significant correlation with palatability was only achieved late in this neuron's responses, possibly because of a floor effect on firing rate).

In summary, the examples in Figure 1 suggest that significant periods of taste responsiveness, taste specificity, and palatability relatedness can often be found in the same LH neuron. In each case, the responses were initially nondistinctive, and subsequently became palatability related and taste specific. Furthermore, taste specificity and palatability relatedness emerged at approximately the same time. The latter finding is unlike what has been observed in gustatory cortex and central amygdale (CeA) (Katz et al., 2001; Sadacca et al., 2012), suggesting that the central aspect of taste-specific LH responding may involve the processing of palatability.

We found that the firing pattern seen in the example neurons-nondistinctive taste responsiveness followed immediately by taste specificity that was entirely palatability related-also characterizes the entire LH population of taste responses. In Figure $2 \mathrm{~A}$, the percentage of $\mathrm{LH}$ neurons that were taste responsive (dashed line) rose rapidly shortly after taste delivery, while tastespecific (gray line) and palatability-related (black line) responses appeared only after the initial nondistinctive responses and exhibited nearly identical time courses. Few LH neurons produced responses related to motivation/intensity (Xs and Os; see Materials and Methods).

As suggested in Figure 1, this progression from responsiveness to specificity/palatability also characterized the responses of many individual neurons. The vast majority of neurons with taste-specific responses (77\%; $27 / 35$ responses) were also significantly taste responsive (nearly $10 \%$ higher than the percentage of taste-responsive neurons in the overall population - suggesting that the two properties were present in the same neuron more often than would be expected by chance. When the onset of taste specificity was plotted against the onset of taste responsiveness for these neurons (Fig. 2B), the data points were located almost exclusively to the left of the unity line, demonstrating that in nearly every LH neuron that conveyed both types of information, a period of taste responsiveness preceded taste specificity. A Wilcoxon signed rank test showed that the difference in onset times was highly significant $\left(Z_{(27)}=-4.3 ; p<0.001\right)$.

We also observed extensive overlap between taste specificity and palatability relatedness in individual LH neurons: approximately two-thirds (66\%; 23/35 LH neurons) of the LH neurons with significant taste-specific responses also had palatabilityrelated responses. Furthermore, when we pitted the onset latency of taste specificity against the onset latency of palatability relatedness in these neurons, the resultant "cloud" of points was tightly clustered along the unity line (Fig. $2 C$; regression slope: $1.1 ; 95 \%$ confidence interval: $0.8-1.3$ ), indicating that these two properties arose concurrently within single-neuron responses. The extent of the overlap is even more striking given the fact that (1) the statistical tests used to classify the neurons are prone to a certain amount of noise, and (2) the two taste properties were assessed independently. The few $(n=7)$ palatability-related responses that were not also taste specific likely reflect differences between rank correlation (which ignores the magnitude of between-taste firing rate differences) and ANOVA (which does not).

Figure $2 C$ suggests that taste-specific LH responses may on the whole be best thought of as palatability related. If this conclusion is valid for the entire population of LH neurons, then the "best stimulus" (the stimulus that most strongly modulates the neuron's response) for each neuron will most likely be either sucrose (the most palatable taste) or quinine (the most aversive taste). If, 
on the other hand, LH responses are simply taste specific in a more general sense, then similar numbers of neurons will respond most strongly to each of the five stimuli-that is, the distribution of best stimuli across the population will be uniform. Figure $2 D$ reveals that the majority $(n=28)$ of the 42 neurons that were either significantly taste specific, significantly palatability related, or both responded most strongly to either sucrose or quinine; in fact, best responses to either sucrose or quinine were observed more than twice as often as best responses to acid, the third most likely occurrence. This distribution of best stimuli differs significantly from a uniform distribution $\left(\chi^{2}(4)=13.2\right.$, $p=0.01$ ), allowing us to reject the hypothesis that $\mathrm{LH}$ responses are purely taste specific. The distribution was not, however, significantly different from an "all quinine or sucrose" distribution $\left(\chi^{2}(4)=4.8, p=0.31\right)$.

We therefore conclude that LH taste responses are not merely taste specific, but are also palatability related. In a later section (Fig. 4C), we will provide convergent evidence for this conclusion, showing that the relatively small percentage $(12 / 35 \mathrm{LH}$ neurons, 34\%) of LH neurons that appeared to contain taste-specific but not palatability-related information are not a separate group (although they are excluded from subsequent analyses of palatability-responsive neurons), but are likely neurons producing palatability-related responses that were not quite robust enough to be detected by our statistical tests. Put simply, and as implied by Figure 2, $C$ and $D$, virtually all of the stimulus specificity observed in LH taste responses appears to be more or less palatability related. The remainder of this article will therefore focus on palatability-related responses.

\section{LH contains two distinct populations of palatability- responsive neurons}

Further analysis revealed that palatability-related LH responses come in two types that differ along the following three basic response parameters: (1) the time course of the evoked response, (2) the baseline firing rate, and (3) the latency to palatabilityrelated firing. The examples displayed in Figure $1, C$ and $D$, are representative members of the two populations. The neuron in Figure $1 D$ produced responses that were far more protracted than those produced by the neuron in Figure $1 C$. In addition, the baseline firing rate in Figure $1 D$ is four times higher than that in Figure 1C. Finally, taste-specific information appears slightly later in Figure $1 D$ than in Figure $1 C$.

The intensity plot in Figure $3 A$ reveals the two possible time courses of taste responses. Each row depicts a separate neuron's evoked response (averaged across all five taste stimuli) as a function of time following taste delivery; each response is normalized to its peak value, with brighter pixels denoting periods of greater response modulation. Responses are ordered according to their latency to peak, with neurons slower to peak placed closer to the bottom of the plot. Neurons in the top half of the stack produced brief responses that peaked within $250-750 \mathrm{~ms}$ but had largely vanished by $1000 \mathrm{~ms}$ (similar to the neuron in Fig. 1C). The responses of the neurons in the bottom half of the stack are more protracted, peaking after $1000 \mathrm{~ms}$ and often remaining elevated until at least $2000 \mathrm{~ms}$ after taste delivery (similar to the neurons in Fig. $1 D, E)$. In line with these observations, a frequency histogram showing the percentage of the total evoked response magnitude contained within the $1000-2000 \mathrm{~ms}$ period (Fig. 3B, top) has two peaks: a sharp peak at $\sim 5 \%$, representing the neurons that occupy the top rows of the intensity plot (for which the vast majority of the responses occurred earlier than $1000 \mathrm{~ms}$ ); and a
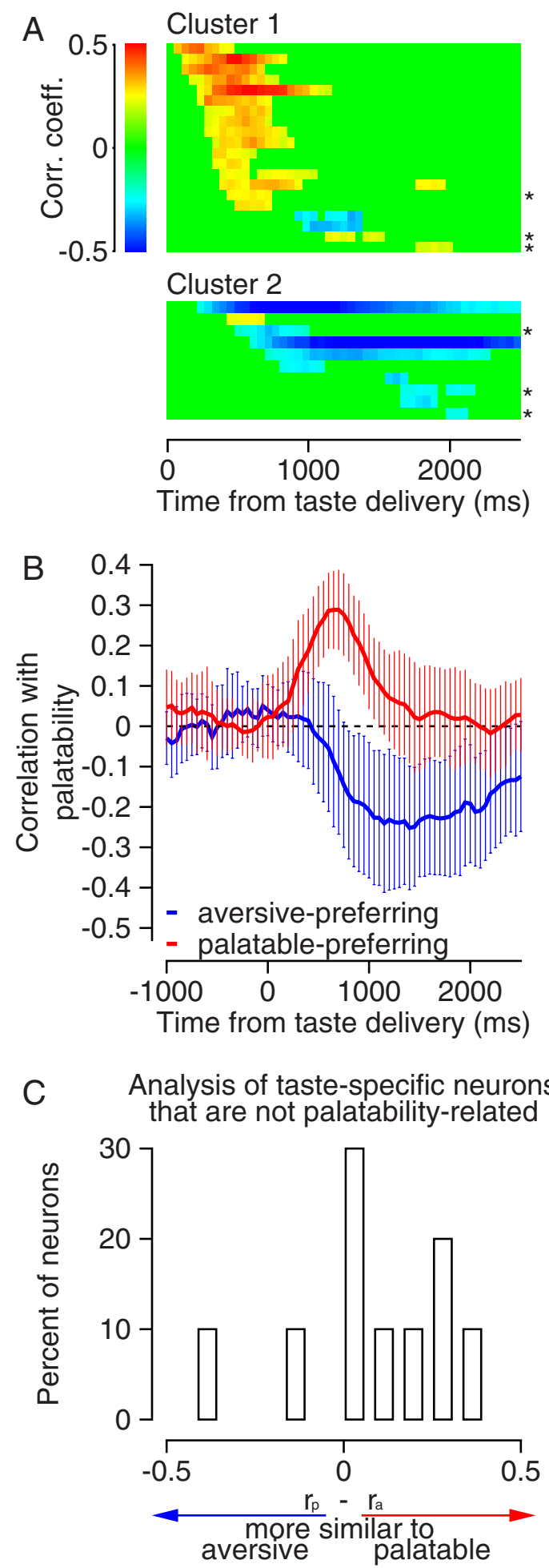

Figure 4. Time course of palatability representations in the two groups of palatability-responsive neurons. $A$, Each intensity plot shows the time course of significant correlations between neural responses and taste palatability for one of the two clusters of neurons identified in Figure 3 C. Individual neurons are plotted in separate rows; asterisks denote neurons with inhibitory responses. Positive correlations (stronger responses to sucrose) are shown in shades of red, negative correlations (stronger responses to quinine) are shown in shades of blue, and nonsignificant correlations are shown in green. The magnitude of the correlation is indicated by the pixel intensity. $\boldsymbol{B}$, The raw correlation with palatability as a function of time from taste delivery, averaged across all palatable-preferring (red) and aversive-preferring (blue) neurons. Error bars denote SDs. The dashed line is centered on zero. $\boldsymbol{C}$, Histogram comparing the palatability correlation functions of 10 (of the 12) "taste specificity-only" neurons with those of the palatable- or aversive-preferring neurons. Positive $r_{p}-r_{a}$ values indicate greater similarity with the palatable-preferring group. 
flatter bump from 30\% onward, made up of neurons situated near the bottom of the intensity plot.

Palatability-responsive neurons were also approximately bimodal with regard to both baseline firing rate and latency to significant palatability-related firing. More than $50 \%$ of the neurons produced $<5$ spikes/s during the baseline period, but for another $16 \%$ the spontaneous firing rate was at least 30 spikes/s (Fig. 3B, middle). Finally, for the majority of the neurons, the onset of palatability relatedness (Fig. 3B, bottom) occurred between 500 and $1000 \mathrm{~ms}$ after taste delivery, but for a separate group palatability relatedness did not reach significance until much later.

When all three response characteristics were taken into account, the neurons arranged themselves into two discrete clusters (Fig. 3C), a grouping that was determined by a $k$-means cluster analysis. Neurons in the first cluster (Fig. 3C, filled circles) tended to have more phasic taste responses, smaller baseline responses, and more rapid onset of palatability-related firing than neurons in the second cluster (Fig. 3C, hollow circles). We evaluated the quality of the $k$-means clustering by comparing the sum of the squared distance (SSD) between each neuron and its cluster centroid for the $k$-means algorithm versus for random partitions of the dataset into correspondingly sized clusters. We found that the SSD for the $k$-means clusters (60.2) was considerably smaller than (and, indeed, out of the range of) the SSD values for 100,000 randomly selected clusters (mean: 84.0; range: 66.1-87.0).

\section{The two groups of LH neurons with palatability-related responses differ with regard to whether they respond best to palatable or aversive tastes}

Note that beyond the initial decision to restrict our analysis to neurons with palatability-related responses, the two population clusters in Figure $3 \mathrm{C}$ were determined in the absence of any direct assessment of the neurons' taste response patterns. We observed, however, that two subpopulations extracted by the clustering analysis also differed in the valence of their palatability representations. Consistent with the examples shown in Figure $1 C-E$, neurons in the first cluster reliably produced stronger responses to palatable stimuli than to aversive stimuli, while neurons assigned to the second cluster showed the reverse activation pattern.

Figure $4 A$ illustrates this dichotomy. For each neuron, the magnitude of the rank correlation between the evoked response and taste palatability is plotted as a function of time (correlation calculated from responses to all deliveries of all five taste stimuli; see Materials and Methods). Red pixels indicate portions of the response that were positively correlated with palatability (i.e., that were best modulated by palatable stimuli), while blue pixels reflect responses that were negatively correlated with palatability (i.e., that were best modulated by aversive stimuli). Green pixels show periods in which the correlation failed to reach statistical significance $(p<0.01)$. With only two exceptions, neurons pulled from the first cluster-neurons with more phasic responses-responded more vigorously to palatable than aversive taste stimuli, as evidenced by the preponderance of red pixels in the top color plot. Similarly, with only one exception, neurons in the second cluster-neurons with more protracted responses- had only blue pixels and thus preferred aversive taste stimuli. For all three exceptions, palatability-related firing was not only relatively modest in strength (weaker pixel intensity) but also short lived (brief duration of red or blue segment).

In addition to the highly reliable relationship between basic response characteristics and palatability valence, we also found that neurons were absolute in their palatability valence: red and blue pixels were never present in the same neuron, even though our analyses did not preclude such an outcome. Therefore, the valence of the palatability-related firing appears to be an abiding functional characteristic differentiating the two kinds of responses identified in Figure 3C. We decided to base all further analyses on the sign of the palatability correlations, referring to neurons with positive correlations (red pixels) as "palatablepreferring neurons" and neurons with negative correlations (blue pixels) as "aversive-preferring neurons."

As suggested above, in Figures $1 C-E$ and $3 B$, bottom, the two types of palatability-related responses had different time courses. In the palatable-preferring neurons, statistically significant correlations with palatability generally appeared between 250 and $750 \mathrm{~ms}$ after taste delivery (latency: $574 \pm 86 \mathrm{~ms}$ ) and were uniformly short lived (interval between earliest and latest occurring red pixel: $466 \pm 68 \mathrm{~ms}$ ). In the aversive-preferring neurons, meanwhile, significant anti-correlations tended to appear at later times (latency: $1178 \pm 162 \mathrm{~ms}$; Wilcoxon rank sum test: $Z_{(30)}=$ $3.2, p=0.001$ ), and were of more variable duration (mean: $691 \pm$ $216 \mathrm{~ms}$; Levene's test for equality of variances: $F_{(1,28)}=6.6$, $p=0.02)$. The overall effect is summarized in Figure $4 B$, which contains the averages of the raw correlation coefficients between neural responses and taste palatability for each subpopulation (red: palatable-preferring neurons; blue: aversive-preferring neurons): neural activity favoring pleasant taste sensations is dominant early in taste processing but is transient, all but disappearing within $1000 \mathrm{~ms}$ of taste delivery. Responses favoring disagreeable taste sensations, meanwhile, appear $\sim 500 \mathrm{~ms}$ after taste delivery, continued to build across the remainder of the first 1000 $\mathrm{ms}$, and persisted until the end of the $2500 \mathrm{~ms}$ analysis period. To confirm that our analysis of palatability produced very few "false positives" during the baseline period, for Figure $4 B$ only we extended our estimates of the palatability correlation functions backward in time to $1000 \mathrm{~ms}$ preceding taste delivery.

\section{The two response types capture virtually all taste-specific LH firing}

Finally, we made use of the strong relationship between basic response characteristics and response patterning to further determine whether all taste-specific LH responses-even those that could not initially be classified as significantly palatability related (and which were therefore not included in the analyses of palatability-responsive neurons) - tend to resemble one of the two palatability-responsive subtypes. Specifically, we tested the hypothesis that the 12 neurons whose responses had previously been categorized as taste specific but not palatability related would, when assigned via basic response properties to one of the two clusters in Figure 3C, appropriately (albeit weakly) match the palatability function of their assigned cluster. Each of the 12 neurons was assigned to the cluster whose centroid was closer (in terms of Euclidean distance) to the neuron's position in the response characteristics space.

We focused on the 10 neurons that were assigned to the palatable-preferring cluster (the two neurons that grouped into the second cluster were too few for interpretable analysis). We assessed the similarity of the response patterns observed in these 10 neurons to those of the palatable- and aversive-preferring groups. Specifically, we computed the Pearson product-moment correlations $(r)$ between the palatability relatedness through time of each of the 10 neurons and those for the palatable-preferring and aversive-preferring groups (respectively, the red and blue traces in Fig. 4B, from $250 \mathrm{~ms}$ onward). This analysis provided two correlations for each of the 10 neurons in question: $r_{a}$ (the 
A

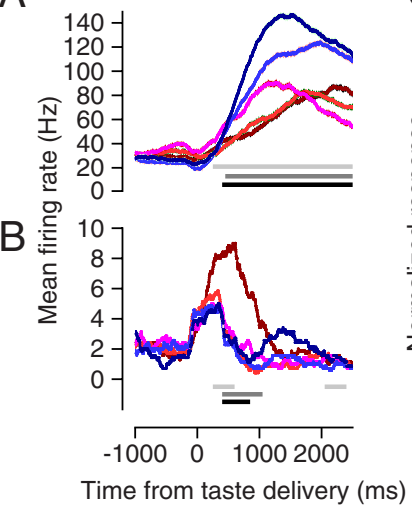

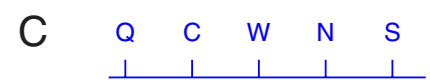

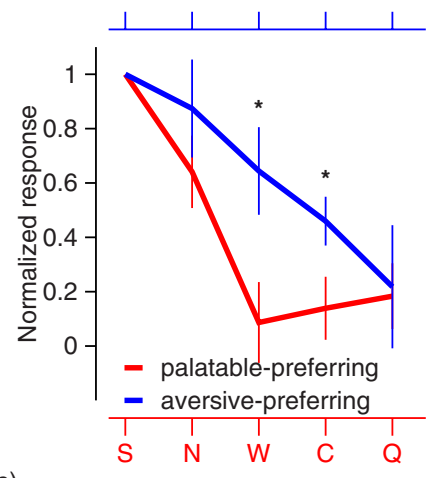

Figure 5. Comparison of the dynamic range of palatable- and aversive-preferring neurons. $A, B$, Each set of colored traces represents the average responses of an example neuron to the five taste stimuli. Each response is smoothed with a $500 \mathrm{~ms}$ rectangular filter. $C$, The thick lines plot the average normalized response curves across all five tastes, in order of strongest to weakest, for the palatable-preferring (red) and the aversive-preferring (blue) neurons. Error bars represent SE measurements across neurons within each group, and asterisks denote statistically significant differences $(p<0.05)$ between the two groups, as determined by a Wilcoxon rank sum test.

correlation between palatability relatedness for that neuron and the aversive-preferring pattern) and $r_{p}$ (the correlation between palatabillity relatedness for that neuron and the palatablepreferring pattern). If $r_{p}>r_{a}$, then the palatability function of the neuron is more similar to the average function from the palatable-preferring group, while the opposite is true if $r_{a}<r_{p}$. When we quantified the value of $r_{p}-r_{a}$ across the 10 neurons (Fig. 4C), we found, in line with our prediction, that 8 of the 10 had positive values and thus were more similar to the palatablepreferring neurons (one-sided sign test that $\mathrm{r}_{\mathrm{p}}>\mathrm{r}_{\mathrm{a}}: p=0.05$ ).

These results suggest that even taste-specific responses that failed to reach significance in palatability relatedness tended to come in two types that are distinguished by their basic response characteristics and palatability representations. That is, virtually all taste-specific LH responses are either phasic and palatable preferring or protracted and aversive preferring.

Palatable- and aversive-preferring LH neurons differ in their breadth of responsiveness and functional connectivity, but not in their general anatomical location

The above analyses separated neurons based on differences in baseline firing rates, response dynamics, and ordering of responses to taste stimuli. In addition, palatable- and aversivepreferring neurons differed in the dynamic range of their taste responses. Aversive-preferring neurons had a broad dynamic range, often responding distinctly to most or all of the five tastes, while palatable-preferring neurons tended to respond strongly and distinctly to only the most palatable tastes, and produced similarly weak responses to aversive tastes. The aversivepreferring neuron displayed in Figure $5 A$, for instance, responded distinctly to at least four tastes (only sucrose and sodium chloride responses were similar). The responses of the aversivepreferring neuron in Figure $1 D$ varied similarly, albeit less evenly, across the entire palatability range: the response to sucrose was smaller than those to citric acid, water, and sodium chloride, which were smaller still than the response to quinine. Contrast these panels with Figures $1 C$ and $5 B$, which show palatablepreferring neurons: each responded strongly to the most palat-

A
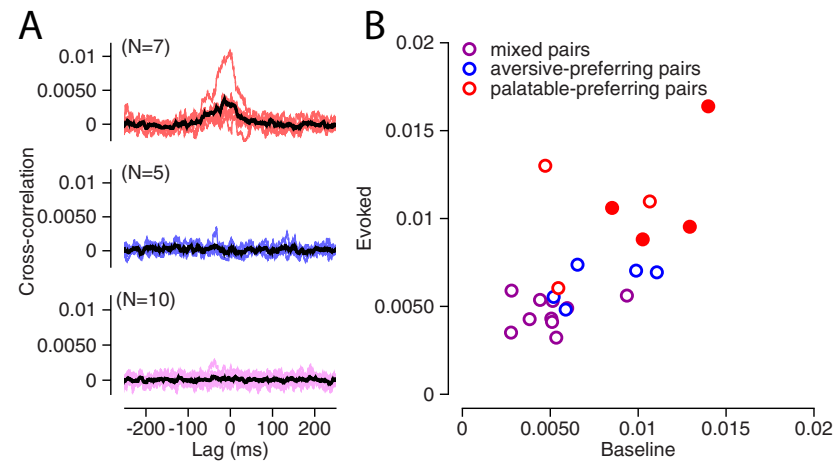

Figure 6. Analysis of the functional connectivity strength between homogeneous and heterogeneous pairs of palatability-responsive neurons. $\boldsymbol{A}$, Each panel shows the full set of raw cross-correlograms ( $x$-axis, time from spike of arbitrarily selected neuron $1 ; y$-axis, correlation reflecting likelihood of a spike in neuron 2) measured for a particular pair type. The top panel contains cross-correlograms from the evoked period for all pairs of palatable-preferring neurons (red traces), the middle panel, all pairs of aversive-preferring neurons (blue traces), and the bottom panel, all mixed pairs (purple traces). The thick black line in each panel denotes the average cross-correlogram for the particular pair type. To aid with visualization, each trace was smoothed with a $10 \mathrm{~ms}$ rectangular filter. $\boldsymbol{B}$, For all pairs, the peak height of the crosscorrelogram from the evoked period ( $y$-axis) is plotted against the peak height from the baseline period ( $x$-axis). The unsmoothed cross-correlograms were used to calculate the peak heights. Palatable-preferring, aversive-preferring, and mixed pairs are represented by red, blue, and purple symbols, respectively. Filled symbols correspond to pairs with statistically significant functional connectivities.

able tastes, but produced smaller and highly similar responses to the three (Fig. 1C) or four (Fig. 5B) least palatable tastes.

Figure $5 C$ verifies that the dynamic ranges observed in the example neurons are characteristic of the two subpopulations. We computed a "palatability tuning curve" for each neuron by normalizing the magnitude of its evoked response to each of the five tastes by the magnitude of its sucrose response (for palatablepreferring neurons) or quinine response (for aversive-preferring neurons). The average tuning curve for the palatable-preferring group (red trace) drops off sharply after the two most palatable tastes and is nearly flat across the three least palatable tastes, whereas the tuning curve for the aversive-preferring group decreases gradually across all five tastes. The difference in curvature was especially marked for the tastes of intermediate palatability: sodium chloride, water, and citric acid. On average, these three tastes produced responses in aversive-preferring neurons that were $66 \pm 11 \%$ of their quinine responses, but activated palatable-preferring neurons to only $29 \pm 9 \%$ of their sucrose responses (Wilcoxon rank sum comparing the difference in activation for the three intermediate tastes: $\left.Z_{(30)}=2.2, p=0.03\right)$.

An entropy analysis of the tuning curves (Smith and Travers, 1979) further confirmed that aversive-preferring neurons had a broader dynamic range than palatable-preferring neurons. By definition, the entropy of each tuning curve ranges between 0 and 1 , where 0 is the narrowest possible tuning curve (neuron responds to only one taste) and increasing values of entropy indicate broader tuning curves. The average entropy of aversive-preferring neurons $(0.90 \pm 0.03)$ was significantly larger than the average entropy of palatable-preferring neurons $(0.77 \pm 0.02)$ (Wilcoxon rank sum test: $\left.Z_{(30)}=3.0, p=0.003\right)$.

We observed one final difference between the two groups of palatability-responsive neurons: the strength of the functional connectivity between simultaneously recorded pairs of palatablepreferring neurons was greater than that for pairs of aversivepreferring neurons, as well as for mixed pairs containing one neuron of each type. Figure $6 A$ plots the cross-correlograms from 
the evoked period, for all 7 pairs of simultaneously recorded palatable-preferring neurons (Fig. $6 \mathrm{~A}$, top, red traces), all 5 pairs of aversive-preferring neurons (Fig. 6A, middle, blue traces), and all 10 mixed pairs (Fig. $6 A$, bottom, purple traces). Figure $6 B$ shows that pairs of palatable-preferring neurons exhibited the strongest functional connectivity, as measured by the peak heights of the cross-correlograms, for both the evoked (0.011 \pm 0.0012 spikes $\left.^{2} / \mathrm{ms}^{2}\right)$ and the baseline periods $(0.010 \pm 0.0013$ spikes ${ }^{2} / \mathrm{ms}^{2}$ ). The cross-correlations for aversive-preferring pairs were weaker (evoked: $0.0063 \pm 0.0005$ spikes ${ }^{2} / \mathrm{ms}^{2}$; baseline: $0.0077 \pm 0.0012$ spikes $^{2} / \mathrm{ms}^{2}$ ), and those for mixed pairs were weaker still (evoked: $0.0047 \pm 0.0003$ spikes ${ }^{2} / \mathrm{ms}^{2}$; baseline: $0.0050 \pm 0.0006$ spikes $^{2} / \mathrm{ms}^{2}$ ). One-way ANOVAs showed that the difference between the pair types was statistically significant for both the evoked $\left(F_{(2,19)}=19.4, p<0.001\right)$ and the baseline periods $\left(F_{(2,19)}=6.3, p=0.008\right)$. The differences remained significant even after the large outlier among the palatablepreferring pairs had been removed (evoked: $F_{(2,18)}=22.8, p<$ 0.001 ; baseline: $\left.F_{(2,18)}=4.96, p=0.02\right)$. Finally, statistically significant functional connectivity was exclusively found among palatable-preferring pairs (Fig. 6B, four filled data points; see Materials and Methods for estimation of statistical significance). All of these four palatable-preferring pairs had statistically significant functional connectivity for both the evoked and the baseline periods. No other pairs reached significance for either period.

Given the many differences between the two groups of palatability-responsive neurons, it might be reasonable to speculate that the neurons are part of separate functional networks. Our histological results indicate, however, that the networks are not anatomically segregated-the two groups of neurons occupy overlapping anteroposterior levels within LH (Fig. 7). Unfortunately, our anatomical data do not have the resolution to determine whether palatable- and aversive-preferring neurons originated from specific subregions within LH that are believed to subserve different functions based on their unique connectivity and neurochemical expression patterns (Goto et al., 2005; Swanson et al., 2005; Hahn and Swanson, 2010). At the macroscopic level, however, the two groups appear interspersed.

\section{Discussion}

\section{Two subpopulations of LH neurons}

The response patterns of LH neurons during the taste experience implicate LH in palatability processing. We identified two groups of neurons within $\mathrm{LH}$, one best activated by palatable tastes, the other by aversive tastes. The two groups could be further distinguished in terms of their (1) response dynamics, (2) baseline firing rates, (3) breadth of responsiveness, and (4) crosscorrelations with other LH neurons. Almost all LH neurons that produced taste-specific responses fell into one of two categories based on analysis of these parameters.

Taste response dynamics have been previously examined in GC and in basolateral amygdala (BLA) and CeA (Katz et al., 2001; Fontanini et al., 2009; Sadacca et al., 2012). Despite LH's direct connections with all three areas (Krettek and Price, 1978; Berk and Finkelstein, 1982; Petrovich et al., 2001; Goto et al., 2005), LH taste response dynamics bear only a limited resemblance to those observed in the other areas. Like in GC, CeA, and much of BLA, the earliest portion of taste responses in LH is nonspecific; in each region, responses become taste specific $\sim 250 \mathrm{~ms}$ after taste delivery. The nature of the information within the tastespecific period differs across areas, however. In GC, the first 500 $\mathrm{ms}$ of this period provides information about the identity of the taste, but not its palatability. In BLA and LH, meanwhile,
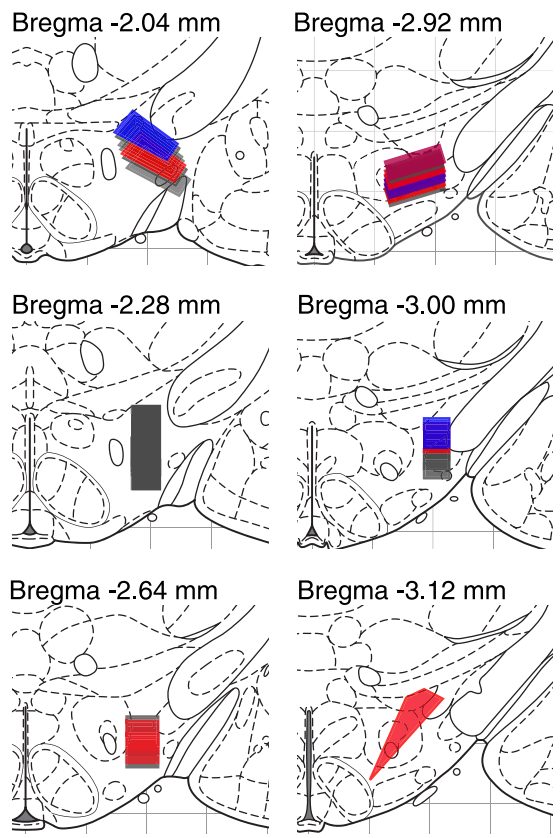

Region contains

- Palatable-preferring

- Aversive-preferring

- Mix of both

- Taste-responsive or -specific only neurons
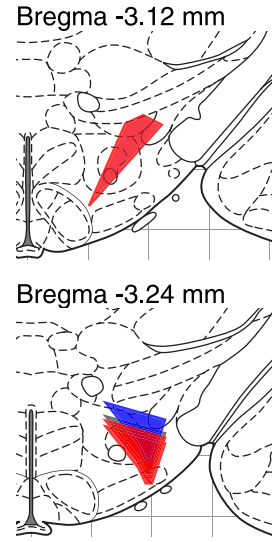

Figure 7. Anatomical organization of the two types of palatability-responsive neurons. Redor blue-shaded regions represent the extent of electrode tip locations from recording sessions that contained palatable- or aversive-preferring neurons. Regions that contained both types of neurons are denoted in purple, with the exact shade chosen to reflect the ratio of palatablepreferring to aversive-preferring neurons within that region. Black-shaded regions represent areas in which we did not find palatability-responsive neurons, but did find neurons with significantly taste-responsive or taste-specific responses.

palatability-related information is present from the onset of taste specificity. The earlier, synchronous appearance of palatability information in BLA and LH suggests that they may work together to process palatability-related information.

Palatability-related information in LH is conveyed by two groups of neurons with distinct but overlapping time courses. BLA neurons with taste-specific responses generally express palatability information across a similar time course as palatablepreferring LH neurons. The time courses of these BLA and LH palatability responses both virtually disappear within $1000 \mathrm{~ms}$ of taste delivery (Fontanini et al., 2009). However, the response patterns of the BLA neurons are more heterogeneous, with only $33 \%$ responding best to palatable tastes. Much of the palatabilityrelated information in GC depends upon input from BLA (Piette et al., 2012); future experiments will dissect the interactions between taste responses in BLA/GC and those in LH, and will examine how these interactions relate to perception.

Later palatability-related responding in $\mathrm{LH}$ is dominated by neurons that prefer aversive tastes. The complementary response characteristics of the two types of LH neurons, in conjunction with their close physical proximity, suggest a scenario in which they may reciprocally modulate each other's activity. The modulation is unlikely to be via direct connections, since we observed stronger functional connectivity between pairs of LH neurons of the same type than between 
mixed pairs. It is more probable that palatable-preferring and aversive-preferring neurons form distinct but interacting functional networks. The taste circuit could conceivably contain two mutually regulating arms of palatability processing, the first consisting of BLA and palatable-preferring LH neurons, the second, aversive-preferring LH neurons.

Several observations suggest that the palatable-preferring neurons described in the present study might be part of the LH feeding center, which consists of a small population of widely projecting neurons that secrete orexin (ORX; Sakurai et al., 1998) or melanin-concentration hormone (MCH; Qu et al., 1996). First, we recorded from a region that is not only necessary for the regulation of feeding behavior (Anand and Brobeck, 1951; Stanley et al., 1993), but is also enriched in ORX+ and $\mathrm{MCH}+$ neurons (Broberger et al., 1998; Sakurai et al., 1998). In addition, the majority of palatable-preferring neurons had baseline firing rates between 0 and $5 \mathrm{~Hz}$, comparable to in vivo measurements from ORX+ neurons (Mileykovskiy et al., 2005; Takahashi et al., 2008); firing rates were much higher in aversive-preferring neurons, marking them as putative interneurons (Csicsvari et al., 1999; Hassani et al., 2009, 2010; Gentet et al., 2010). Finally, ORX+ neurons project densely to the amygdala (Schmitt et al., 2012), consistent with possible cooperation between palatable-preferring LH neurons and BLA in processing tastes. While the precise identity of our neurons remains speculative at present, future experiments will directly probe the neurochemical content of $\mathrm{LH}$ neurons with specific patterns of taste responses.

\section{LH's role in behavior}

In addition to feeding, LH has been implicated in other tasterelated behaviors, including basic palatability perception: specifically, LH-ablated animals exhibit increased absolute preference/ aversion thresholds to saccharin (Ferssiwi et al., 1987). Palatability information in LH emerges between 250 and $500 \mathrm{~ms}$, which precedes and could potentially drive palatability-related orofacial behaviors that typically appear around or after $1000 \mathrm{~ms}$ (Travers and Norgren, 1986). LH ablation also impacts learning paradigms such as conditioned taste preference and conditioned taste aversion (Roth et al., 1973; Berridge et al., 1981; Caulliez et al., 1996; Forestell and LoLordo, 2003), with the consequences being greater for the former (Touzani and Sclafani, 2001, 2002), although the latter still elicits electrophysiological and neurochemical changes in LH (Aleksanyan et al., 1976; West et al., 1991; Tucci et al., 1998). LH therefore appears to be more central to the circuit for taste-preference learning than taste-aversion learning, consistent with our functional connectivity results suggesting that palatable-preferring LH neurons are part of a more cohesive network than aversive-preferring neurons.

Many taste-related behaviors, including feeding and conditioned taste aversion, have both palatability and motivationrelated components, which, while not identical, are nonetheless highly correlated (Galaverna et al., 1993; Berridge, 1996; Rana and Parker, 2008; Overduin et al., 2012). LH is likely involved in both processes: it is anatomically connected to palatability- and motivation-related "hotspots," such as the nucleus accumbens shell and the amygdala (Krettek and Price, 1978; Berridge and Robinson, 2003; Tsumori et al., 2006; Thompson and Swanson, 2010). Furthermore, stimulation of LH increases both consumption and the production of orofacial behaviors that signal aversion (Berridge and Valenstein, 1991), which may reflect coactivation of the two types of neurons with opposite response patterns.
These facts suggest that it is reasonable to begin an investigation of taste responses in LH by looking at either palatability or motivation, with the understanding that information about either property is likely informative about the other. We chose to use the term "palatability" here for the following reasons. First, motivation is typically assessed by an animal's efforts in seeking out a particular stimulus, but in our study taste delivery was not under the rat's control. Also, we measured responses to inherently meaningful stimuli, which, when delivered in the same manner as in our study, elicit the orofacial behaviors that have been used to determine palatability (Grill and Norgren, 1978; Berridge and Valenstein, 1991; Peciña and Berridge, 2005). Finally, most studies of neural taste responses have described these responses in terms of palatability.

Our finding of two palatability-responsive LH populations bears some resemblance to an earlier study that identified distinct groups of rabbit LH neurons differentially excited by auditory cues predicting either the delivery of a palatable or an aversive taste. Many of these neurons expressed taste responses that were congruent with their cue responses (Schwartzbaum, 1988). Unfortunately, it is difficult to directly compare the two studies because they were performed under very different experimental conditions. In the older study, both the timing and identity of an impending taste were predictable. Moreover, Schwartzbaum (1988) delivered taste stimuli via multiple slow pulses, while our rats experienced a single brief pulse. Finally, the rabbits were food deprived, while our rats were water deprived. Each of these conditions can impact neural responses (Di Lorenzo et al., 2003; de Araujo et al., 2006; Samuelsen et al., 2012).

Possibly because he explored a larger swath of LH than we did, Schwartzbaum's (1988) two types of neurons were enriched in separate anteroposterior regions. Electrical stimulation of each region elicited opposing behavioral reactions consistent with either a generalized pleasurable or aversive experience (Schwartzbaum and Leventhal, 1990). Thus, while any parallels between the Schwartzbaum (1988) and Schwartzbaum and Leventhal (1990) studies and our work are necessarily tempered by considerable empirical differences, they nonetheless suggest that our palatability-responsive neurons may be part of more comprehensive motivational networks.

Although our findings speak solely to LH's role in taste processing, they are consistent with several previous studies suggesting that LH may be broadly involved in signaling emotional value across sensory modalities. Strong anatomical connections, and in some cases, functionally relevant interactions, exist between LH and areas involved in learning and addiction, including the amygdala (Krettek and Price, 1978; Tsumori et al., 2006), the nucleus accumbens (Kirouac and Ganguly, 1995; Stratford and Kelley, 1999; Sano and Yokoi, 2007), and the orbitofrontal cortex (Leonard et al., 1969), all of which also contain both palatabilityrelated responses (Zald et al., 2002; Taha and Fields, 2005; Fontanini et al., 2009; Rolls, 2009, 2012) and "value-related" responses to non-taste stimuli (Paton et al., 2006; Sabatinelli et al., 2007). Moreover, LH neurons have been found to respond selectively to non-taste-related rewarding and aversive stimuli (Ono et al., 1986) in a manner that is sensitive to dopaminergic and cholinergic modulation (Fukuda et al., 1990; Ono et al., 1992). The extant data are consistent with a model of LH as an integral part of a generalized circuit through which streams of external and internal sensory information are influenced by neuromodulatory signals to motivate and guide behavior. 


\section{References}

Aleksanyan ZA, Buresová O, Bures J (1976) Modification of unit responses to gustatory stimuli by conditioned taste aversion in rats. Physiol Behav 17:173-179. CrossRef Medline

Anand BK, Brobeck JR (1951) Localization of a "feeding center" in the hypothalamus of the rat. Proc Soc Exp Biol Med 77:323-324. Medline

Anderson AK, Christoff K, Stappen I, Panitz D, Ghahremani DG, Glover G, Gabrieli JD, Sobel N (2003) Dissociated neural representations of intensity and valence in human olfaction. Nat Neurosci 6:196-202. CrossRef Medline

Berk ML, Finkelstein JA (1982) Efferent connections of the lateral hypothalamic area of the rat: an autoradiographic investigation. Brain Res Bull 8:511-526. CrossRef Medline

Berridge KC (1996) Food reward: brain substrates of wanting and liking. Neurosci Biobehav Rev 20:1-25. CrossRef Medline

Berridge KC, Robinson TE (2003) Parsing reward. Trends Neurosci 26:507513. CrossRef Medline

Berridge KC, Valenstein ES (1991) What psychological process mediates feeding evoked by electrical stimulation of the lateral hypothalamus? Behav Neurosci 105:3-14. CrossRef Medline

Berridge K, Grill HJ, Norgren R (1981) Relation of consummatory responses and preabsorptive insulin release to palatability and learned taste aversions. J Comp Physiol Psychol 95:363-382. CrossRef Medline

Berthoud HR, Münzberg H (2011) The lateral hypothalamus as integrator of metabolic and environmental needs: from electrical self-stimulation to opto-genetics. Physiol Behav 104:29-39. CrossRef Medline

Blood AJ, Zatorre RJ, Bermudez P, Evans AC (1999) Emotional responses to pleasant and unpleasant music correlate with activity in paralimbic brain regions. Nat Neurosci 2:382-387. CrossRef Medline

Breslin PA, Spector AC, Grill HJ (1992) A quantitative comparison of taste reactivity behaviors to sucrose before and after lithium chloride pairings: a unidimensional account of palatability. Behav Neurosci 106:820-836. CrossRef Medline

Broberger C, De Lecea L, Sutcliffe JG, Hökfelt T (1998) Hypocretin/orexinand melanin-concentrating hormone-expressing cells form distinct populations in the rodent lateral hypothalamus: relationship to the neuropeptide $\mathrm{Y}$ and agouti gene-related protein systems. J Comp Neurol 402:460474. CrossRef Medline

Bueter M, Miras AD, Chichger H, Fenske W, Ghatei MA, Bloom SR, Unwin RJ, Lutz TA, Spector AC, le Roux CW (2011) Alterations of sucrose preference after Roux-en-Y gastric bypass. Physiol Behav 104:709-721. CrossRef Medline

Burton MJ, Rolls ET, Mora F (1976) Effects of hunger on the responses of neurons in the lateral hypothalamus to the sight and taste of food. Exp Neurol 51:668-677. CrossRef Medline

Caulliez R, Meile MJ, Nicolaidis S (1996) A lateral hypothalamic D1 dopaminergic mechanism in conditioned taste aversion. Brain Res 729:234245. CrossRef Medline

Chen X, Gabitto M, Peng Y, Ryba NJ, Zuker CS (2011) A gustotopic map of taste qualities in the mammalian brain. Science 333:1262-1266. CrossRef Medline

Clarke SN, Ossenkopp KP (1998) Taste reactivity responses in rats: influence of sex and the estrous cycle. Am J Physiol 274:R718-R724. Medline

Csicsvari J, Hirase H, Czurkó A, Mamiya A, Buzsáki G (1999) Oscillatory coupling of hippocampal pyramidal cells and interneurons in the behaving rat. J Neurosci 19:274-287. Medline

de Araujo IE, Gutierrez R, Oliveira-Maia AJ, Pereira A Jr, Nicolelis MA, Simon SA (2006) Neural ensemble coding of satiety states. Neuron 51: 483-494. CrossRef Medline

Dess NK (2000) Responses to basic taste qualities in rats selectively bred for high versus low saccharin intake. Physiol Behav 69:247-257. CrossRef Medline

Di Lorenzo PM, Lemon CH, Reich CG (2003) Dynamic coding of taste stimuli in the brainstem: effects of brief pulses of taste stimuli on subsequent taste responses. J Neurosci 23:8893-8902. Medline

Ferssiwi A, Cardo B, Velley L (1987) Gustatory preference-aversion thresholds are increased by ibotenic acid lesion of the lateral hypothalamus in the rat. Brain Res 437:142-150. CrossRef Medline

Fontanini A, Katz DB (2006) State-dependent modulation of time-varying gustatory responses. J Neurophysiol 96:3183-3193. CrossRef Medline

Fontanini A, Grossman SE, Figueroa JA, Katz DB (2009) Distinct subtypes of basolateral amygdala taste neurons reflect palatability and reward. J Neurosci 29:2486-2495. CrossRef Medline

Forestell CA, LoLordo VM (2003) Palatability shifts in taste and flavour preference conditioning. Q J Exp Psychol B 56:140-160. CrossRef Medline

Formaker BK, Frank ME (1996) Responses of the hamster chorda tympani nerve to binary component taste stimuli: evidence for peripheral gustatory mixture interactions. Brain Res 727:79-90. CrossRef Medline

Frank ME (2000) Neuron types, receptors, behavior, and taste quality. Physiol Behav 69:53-62. CrossRef Medline

Frank ME, Formaker BK, Hettinger TP (2003) Taste responses to mixtures: analytic processing of quality. Behav Neurosci 117:228-235. CrossRef Medline

Fukuda M, Ono T, Nishino H, Nakamura K (1986) Neuronal responses in monkey lateral hypothalamus during operant feeding behavior. Brain Res Bull 17:879-883. CrossRef Medline

Fukuda M, Ono T, Nakamura K, Tamura R (1990) Dopamine and ACh involvement in plastic learning by hypothalamic neurons in rats. Brain Res Bull 25:109-114. CrossRef Medline

Galaverna OG, Seeley RJ, Berridge KC, Grill HJ, Epstein AN, Schulkin J (1993) Lesions of the central nucleus of the amygdala. I: Effects on taste reactivity, taste aversion learning and sodium appetite. Behav Brain Res 59:11-17. CrossRef Medline

Gentet LJ, Avermann M, Matyas F, Staiger JF, Petersen CC (2010) Membrane potential dynamics of GABAergic neurons in the barrel cortex of behaving mice. Neuron 65:422-435. CrossRef Medline

Geran LC, Travers SP (2009) Bitter-responsive gustatory neurons in the rat parabrachial nucleus. J Neurophysiol 101:1598-1612. CrossRef Medline

Goto M, Canteras NS, Burns G, Swanson LW (2005) Projections from the subfornical region of the lateral hypothalamic area. J Comp Neurol 493 : 412-438. CrossRef Medline

Grabenhorst F, Rolls ET, Parris BA, d'Souza AA (2010) How the brain represents the reward value of fat in the mouth. Cereb Cortex 20:1082-1091. CrossRef Medline

Grill HJ, Norgren R (1978) The taste reactivity test. I. Mimetic responses to gustatory stimuli in neurologically normal rats. Brain Res 143:263-279. CrossRef Medline

Grossman SE, Fontanini A, Wieskopf JS, Katz DB (2008) Learning-related plasticity of temporal coding in simultaneously recorded amygdalacortical ensembles. J Neurosci 28:2864-2873. CrossRef Medline

Grossman SP, Dacey D, Halaris AE, Collier T, Routtenberg A (1978) Aphagia and adipsia after preferential destruction of nerve cell bodies in hypothalamus. Science 202:537-539. CrossRef Medline

Haddad R, Weiss T, Khan R, Nadler B, Mandairon N, Bensafi M, Schneidman E, Sobel N (2010) Global features of neural activity in the olfactory system form a parallel code that predicts olfactory behavior and perception. J Neurosci 30:9017-9026. CrossRef Medline

Hagan JJ, Leslie RA, Patel S, Evans ML, Wattam TA, Holmes S, Benham CD, Taylor SG, Routledge C, Hemmati P, Munton RP, Ashmeade TE, Shah AS, Hatcher JP, Hatcher PD, Jones DN, Smith MI, Piper DC, Hunter AJ, Porter RA, et al (1999) Orexin A activates locus coeruleus cell firing and increases arousal in the rat. Proc Natl Acad Sci U S A 96:10911-10916. CrossRef Medline

Hahn JD, Swanson LW (2010) Distinct patterns of neuronal inputs and outputs of the juxtaparaventricular and suprafornical regions of the lateral hypothalamic area in the male rat. Brain Res Rev 64:14-103. CrossRef Medline

Hassani OK, Lee MG, Jones BE (2009) Melanin-concentrating hormone neurons discharge in a reciprocal manner to orexin neurons across the sleep-wake cycle. Proc Natl Acad Sci U S A 106:2418-2422. CrossRef Medline

Hassani OK, Henny P, Lee MG, Jones BE (2010) GABAergic neurons intermingled with orexin and $\mathrm{MCH}$ neurons in the lateral hypothalamus discharge maximally during sleep. Eur J Neurosci 32:448-457. CrossRef Medline

Hoebel BG, Teitelbaum P (1962) Hypothalamic control of feeding and selfstimulation. Science 135:375-377. CrossRef Medline

Katz DB, Simon SA, Nicolelis MA (2001) Dynamic and multimodal responses of gustatory cortical neurons in awake rats. J Neurosci 21:44784489. Medline

Kirouac GJ, Ganguly PK (1995) Topographical organization in the nucleus 
accumbens of afferents from the basolateral amygdala and efferents to the lateral hypothalamus. Neuroscience 67:625-630. CrossRef Medline

Krettek JE, Price JL (1978) Amygdaloid projections to subcortical structures within the basal forebrain and brainstem in the rat and cat. J Comp Neurol 178:225-254. CrossRef Medline

Leonard CM (1969) The prefrontal cortex of the rat. I. Cortical projection of the mediodorsal nucleus. II. Efferent connections. Brain Res 12:321-343. CrossRef Medline

Maier JX, Katz DB (2013) Neural dynamics in response to binary taste mixtures. J Neurophysiol 109:2108-2117. CrossRef Medline

Margules DL, Olds J (1962) Identical "feeding" and "rewarding" systems in the lateral hypothalamus of rats. Science 135:374-375. CrossRef Medline

Mileykovskiy BY, Kiyashchenko LI, Siegel JM (2005) Behavioral correlates of activity in identified hypocretin/orexin neurons. Neuron 46:787-798. CrossRef Medline

Nishijo H, Uwano T, Tamura R, Ono T (1998) Gustatory and multimodal neuronal responses in the amygdala during licking and discrimination of sensory stimuli in awake rats. J Neurophysiol 79:21-36. Medline

Norgren R (1970) Gustatory responses in the hypothalamus. Brain Res 21: 63-77. CrossRef Medline

Ogawa M, van der Meer MA, Esber GR, Cerri DH, Stalnaker TA, Schoenbaum G (2013) Risk-responsive orbitofrontal neurons track acquired salience. Neuron 77:251-258. CrossRef Medline

Ono T, Nakamura K, Nishijo H, Fukuda M (1986) Hypothalamic neuron involvement in integration of reward, aversion, and cue signals. J Neurophysiol 56:63-79. Medline

Ono T, Nakamura K, Fukuda M, Kobayashi T (1992) Catecholamine and acetylcholine sensitivity of rat lateral hypothalamic neurons related to learning. J Neurophysiol 67:265-279. Medline

Overduin J, Figlewicz DP, Bennett-Jay J, Kittleson S, Cummings DE (2012) Ghrelin increases the motivation to eat, but does not alter food palatability. Am J Physiol Regul Integr Comp Physiol 303:R259-R269. CrossRef Medline

Paton JJ, Belova MA, Morrison SE, Salzman CD (2006) The primate amygdala represents the positive and negative value of visual stimuli during learning. Nature 439:865-870. CrossRef Medline

Paxinos G, Watson C (2007) The rat brain in stereotaxic coordinates, Ed. 6. Amsterdam: Academic/Elsevier.

Peciña S, Berridge KC (2005) Hedonic hot spot in nucleus accumbens shell: where do mu-opioids cause increased hedonic impact of sweetness? J Neurosci 25:11777-11786. CrossRef Medline

Petrovich GD, Canteras NS, Swanson LW (2001) Combinatorial amygdalar inputs to hippocampal domains and hypothalamic behavior systems. Brain Res Brain Res Rev 38:247-289. CrossRef Medline

Piette CE, Baez-Santiago MA, Reid EE, Katz DB, Moran A (2012) Inactivation of basolateral amygdala specifically eliminates palatability-related information in cortical sensory responses. J Neurosci 32:9981-9991. CrossRef Medline

Qu D, Ludwig DS, Gammeltoft S, Piper M, Pelleymounter MA, Cullen MJ, Mathes WF, Przypek R, Kanarek R, Maratos-Flier E (1996) A role for melanin-concentrating hormone in the central regulation of feeding behaviour. Nature 380:243-247. CrossRef Medline

Rana SA, Parker LA (2008) Differential effects of neurotoxin-induced lesions of the basolateral amygdala and central nucleus of the amygdala on lithium-induced conditioned disgust reactions and conditioned taste avoidance. Behav Brain Res 189:284-297. CrossRef Medline

Reilly S, Pritchard TC (1996) Gustatory thalamus lesions in the rat: I. Innate taste preferences and aversions. Behav Neurosci 110:737-745. CrossRef Medline

Roitman JD, Shadlen MN (2002) Response of neurons in the lateral intraparietal area during a combined visual discrimination reaction time task. J Neurosci 22:9475-9489. Medline

Rolls ET (2009) Functional neuroimaging of umami taste: what makes umami pleasant? Am J Clin Nutr 90:804S-813S. CrossRef Medline

Rolls ET (2012) Taste, olfactory and food texture reward processing in the brain and the control of appetite. Proc Nutr Soc 71:488-501. CrossRef Medline

Rosen AM, Di Lorenzo PM (2012) Neural coding of taste by simultaneously recorded cells in the nucleus of the solitary tract of the rat. J Neurophysiol 108:3301-3312. CrossRef Medline

Rosen AM, Roussin AT, Di Lorenzo PM (2010) Water as an independent taste modality. Front Neurosci 4:175. CrossRef Medline
Roth SR, Schwartz M, Teitelbaum P (1973) Failure of recovered lateral hypothalamic rats to learn specific food aversions. J Comp Physiol Psychol 83:184-197. CrossRef Medline

Sabatinelli D, Bradley MM, Lang PJ, Costa VD, Versace F (2007) Pleasure rather than salience activates human nucleus accumbens and medial prefrontal cortex. J Neurophysiol 98:1374-1379. CrossRef Medline

Sadacca BF, Rothwax JT, Katz DB (2012) Sodium concentration coding gives way to evaluative coding in cortex and amygdala. J Neurosci 32 9999-10011. CrossRef Medline

Sakurai T, Amemiya A, Ishii M, Matsuzaki I, Chemelli RM, Tanaka H, Williams SC, Richardson JA, Kozlowski GP, Wilson S, Arch JR, Buckingham RE, Haynes AC, Carr SA, Annan RS, McNulty DE, Liu WS, Terrett JA, Elshourbagy NA, Bergsma DJ, et al (1998) Orexins and orexin receptors: a family of hypothalamic neuropeptides and $\mathrm{G}$ protein-coupled receptors that regulate feeding behavior. Cell 92:573-585. CrossRef Medline

Samuelsen CL, Gardner MP, Fontanini A (2012) Effects of cue-triggered expectation on cortical processing of taste. Neuron 74:410-422. CrossRef Medline

Sano H, Yokoi M (2007) Striatal medium spiny neurons terminate in a distinct region in the lateral hypothalamic area and do not directly innervate orexin/hypocretin- or melanin-concentrating hormone-containing neurons. J Neurosci 27:6948-6955. CrossRef Medline

Schmitt O, Usunoff KG, Lazarov NE, Itzev DE, Eipert P, Rolfs A, Wree A (2012) Orexinergic innervation of the extended amygdala and basal ganglia in the rat. Brain Struct Funct 217:233-256. CrossRef Medline

Schwartzbaum JS (1988) Electrophysiology of taste, feeding and reward in lateral hypothalamus of rabbit. Physiol Behav 44:507-526. CrossRef Medline

Schwartzbaum JS, Leventhal TO (1990) Neural substrates of behavioral aversion in lateral hypothalamus of rabbits. Brain Res 507:85-91. CrossRef Medline

Small DM, Gregory MD, Mak YE, Gitelman D, Mesulam MM, Parrish T (2003) Dissociation of neural representation of intensity and affective valuation in human gustation. Neuron 39:701-711. CrossRef Medline

Smith DV, Travers JB (1979) A metric for the breadth of gustatory neurons. Chem Senses 4:215-229. CrossRef

Spector AC, Travers SP (2005) The representation of taste quality in the mammalian nervous system. Behav Cogn Neurosci Rev 4:143-191. CrossRef Medline

Stanley BG, Magdalin W, Seirafi A, Thomas WJ, Leibowitz SF (1993) The perifornical area: the major focus of (a) patchily distributed hypothalamic neuropeptide Y-sensitive feeding system(s). Brain Res 604:304-317. CrossRef Medline

Stewart RB, Russell RN, Lumeng L, Li TK, Murphy JM (1994) Consumption of sweet, salty, sour, and bitter solutions by selectively bred alcoholpreferring and alcohol-nonpreferring lines of rats. Alcohol Clin Exp Res 18:375-381. CrossRef Medline

Stratford TR, Kelley AE (1999) Evidence of a functional relationship between the nucleus accumbens shell and lateral hypothalamus subserving the control of feeding behavior. J Neurosci 19:11040-11048. Medline

Swanson LW, Sanchez-Watts G, Watts AG (2005) Comparison of melaninconcentrating hormone and hypocretin/orexin mRNA expression patterns in a new parceling scheme of the lateral hypothalamic zone. Neurosci Lett 387:80-84. CrossRef Medline

Taha SA, Fields HL (2005) Encoding of palatability and appetitive behaviors by distinct neuronal populations in the nucleus accumbens. J Neurosci 25:1193-1202. CrossRef Medline

Takahashi K, Lin JS, Sakai K (2008) Neuronal activity of orexin and nonorexin waking-active neurons during wake-sleep states in the mouse. Neuroscience 153:860-870. CrossRef Medline

Thompson RH, Swanson LW (2010) Hypothesis-driven structural connectivity analysis supports network over hierarchical model of brain architecture. Proc Natl Acad Sci U S A 107:15235-15239. CrossRef Medline

Touzani K, Sclafani A (2001) Conditioned flavor preference and aversion: role of the lateral hypothalamus. Behav Neurosci 115:84-93. CrossRef Medline

Touzani K, Sclafani A (2002) Lateral hypothalamic lesions impair flavournutrient and flavour-toxin trace learning in rats. Eur J Neurosci 16:24252433. CrossRef Medline

Travers JB, Norgren R (1986) Electromyographic analysis of the ingestion and rejection of sapid stimuli in the rat. Behav Neurosci 100:544-555. CrossRef Medline 
Tsumori T, Yokota S, Kishi T, Qin Y, Oka T, Yasui Y (2006) Insular cortical and amygdaloid fibers are in contact with posterolateral hypothalamic neurons projecting to the nucleus of the solitary tract in the rat. Brain Res 1070:139-144. CrossRef Medline

Tucci S, Rada P, Hernandez L (1998) Role of glutamate in the amygdala and lateral hypothalamus in conditioned taste aversion. Brain Res 813:44-49. CrossRef Medline

West HL, Mark GP, Hoebel BG (1991) Effects of conditioned taste aversion on extracellular serotonin in the lateral hypothalamus and hippocampus of freely moving rats. Brain Res 556:95-100. CrossRef Medline
Yamamoto T, Yuyama N, Kato T, Kawamura Y (1985) Gustatory responses of cortical neurons in rats. II. Information processing of taste quality. J Neurophysiol 53:1356-1369. Medline

Yamamoto T, Matsuo R, Kiyomitsu Y, Kitamura R (1989) Response properties of lateral hypothalamic neurons during ingestive behavior with special reference to licking of various taste solutions. Brain Res 481:286297. CrossRef Medline

Zald DH, Hagen MC, Pardo JV (2002) Neural correlates of tasting concentrated quinine and sugar solutions. J Neurophysiol 87:1068-1075. Medline 